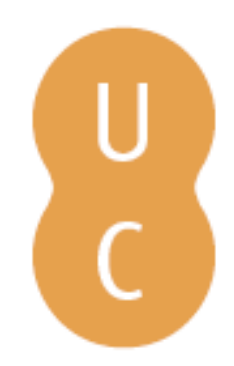

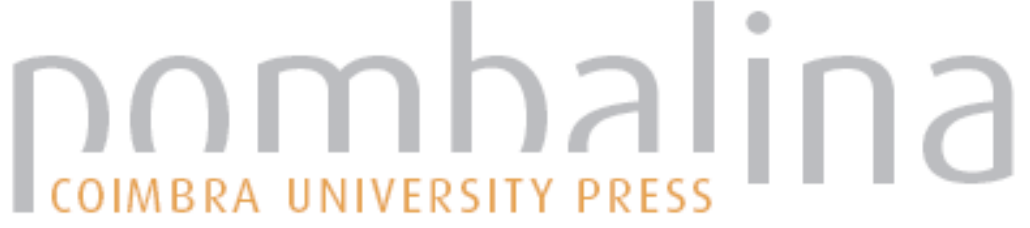

Memória, história e discursos identitários: contributos para um debate

Autor(es): Mota, Luís

Publicado por: Imprensa da Universidade de Coimbra

URL

persistente: URI:http://hdl.handle.net/10316.2/31635

DOI: $\quad$ DOI:http://dx.doi.org/10.14195/978-989-26-0199-1_27

Accessed : $\quad$ 26-Apr-2023 15:48:06

A navegação consulta e descarregamento dos títulos inseridos nas Bibliotecas Digitais UC Digitalis, UC Pombalina e UC Impactum, pressupõem a aceitação plena e sem reservas dos Termos e Condições de Uso destas Bibliotecas Digitais, disponíveis em https://digitalis.uc.pt/pt-pt/termos.

Conforme exposto nos referidos Termos e Condições de Uso, o descarregamento de títulos de acesso restrito requer uma licença válida de autorização devendo o utilizador aceder ao(s) documento(s) a partir de um endereço de IP da instituição detentora da supramencionada licença.

Ao utilizador é apenas permitido o descarregamento para uso pessoal, pelo que o emprego do(s) título(s) descarregado(s) para outro fim, designadamente comercial, carece de autorização do respetivo autor ou editor da obra.

Na medida em que todas as obras da UC Digitalis se encontram protegidas pelo Código do Direito de Autor e Direitos Conexos e demais legislação aplicável, toda a cópia, parcial ou total, deste documento, nos casos em que é legalmente admitida, deverá conter ou fazer-se acompanhar por este aviso. 
Maria Manuela Tavares Ribeiro

Coordenação

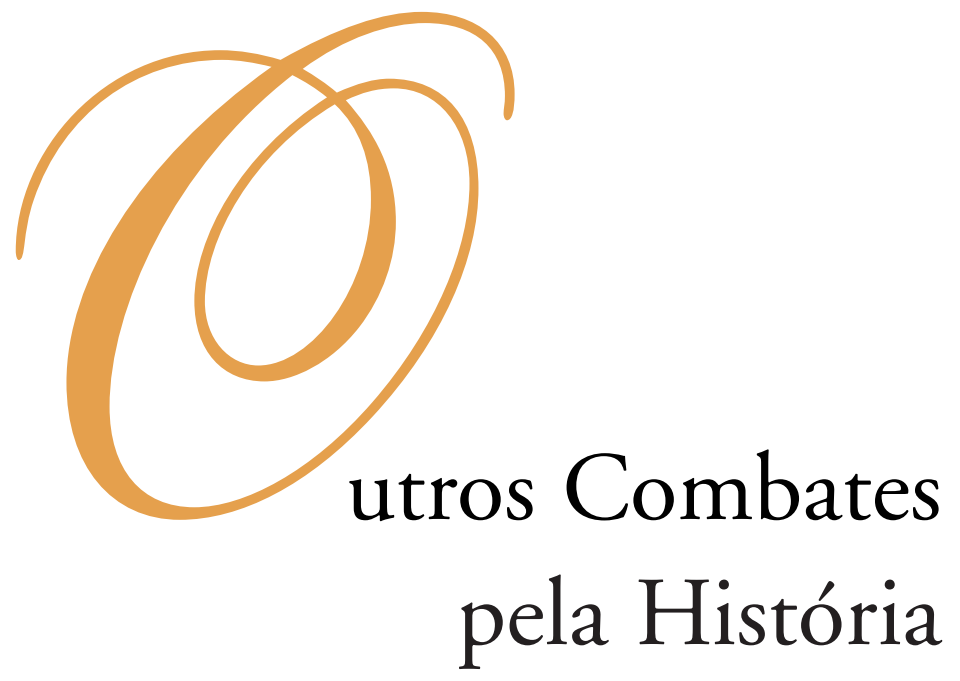




\section{COORDENAÇĀO EDITORIAL}

Imprensa da Universidade de Coimbra

Email: imprensauc@ci.uc.pt

URL: http://www.uc.pt/imprensa_uc

Vendas online: http://livrariadaimprensa.com

\section{CONCEPÇÃO GRÁFICA}

António Barros

\section{ORgANIZAÇĀO DOS TEXTOS}

Isabel Maria Luciano

Marlene Taveira

PRÉ-IMPRESSÃO

António Resende

Imprensa da Universidade de Coimbra

EXECUÇÃO GRÁFICA

SerSilito • Maia

ISBN

978-989-26-0041-3

DEPósito LEGAL

OBRA PUBLICADA COM O APOIO DE:

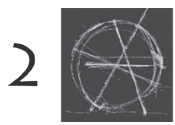

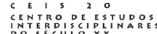

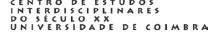

FCT Fundação para a Ciência e a Tecnologia

MINISTÉRIO DA CIÊNCIA, TECNOLOGIA E ENSINO SUPERIOR Portugal

Programa Operacional Ciência, Tecnologia, INOVAÇĀo DO QUADRo COMUNITÁRIO DE APOIO III

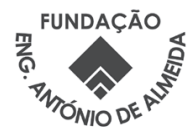

C JULHO 2010, IMPRENSA DA UNIVERSIDADE DE COIMBRA 
Maria Manuela Tavares Ribeiro

Coordenação

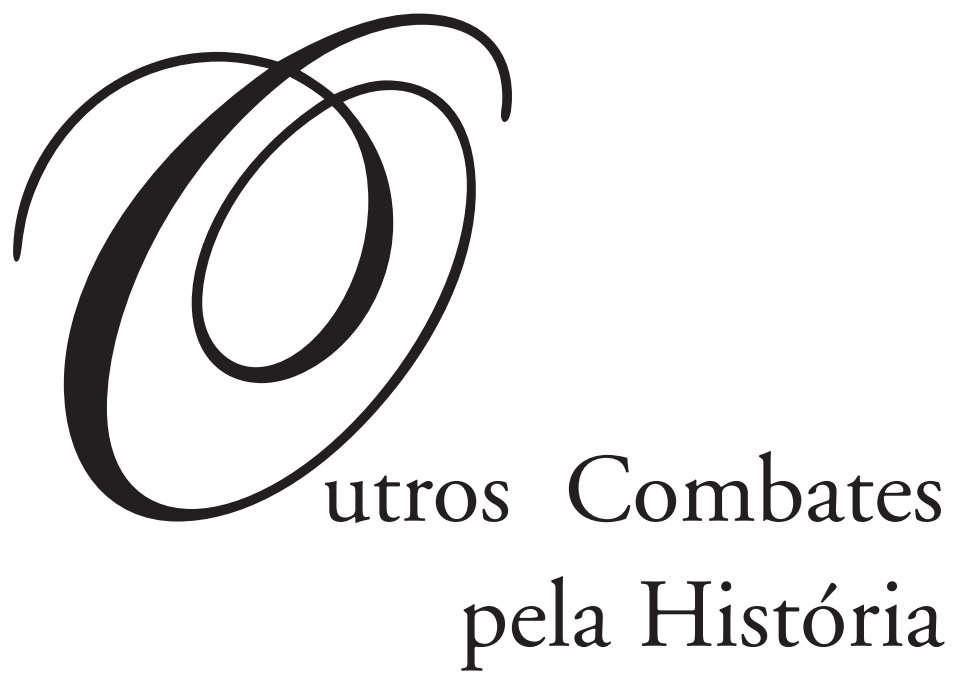

- colmbra 2010 
história, EducaÇÃo e ComunicaÇão 


\section{Luís Mota}

\section{Memória, História e Discursos Identitários. CONTRIBUTOS PARA UM DEBATE}

Neste trabalho ${ }^{1}$ coloco o enfoque nas relaçôes entre Memória e História procurando apresentar uma construção teórica que saliente a importância da complementaridade entre Memória e História e reconheça, e valorize, o papel do sujeito na narrativa histórica. Discuto as principais conclusões do estudo da Escola do Magistério Primário de Coimbra (1942-1989) que se centrou nos discursos dos actores — professores, professoras, alunos e alunas — percebidos como acção, confrontando a análise dos produzidos na imprensa escolar com os enunciados em situação de entrevista. Inicio por uma abordagem à memória, que os gregos traduziam por mneme, referência à lembrança, algo de passivo, e por anamnesis, significando procura activa de recordaçôes ${ }^{2}$.

\section{Memória pessoal, memória colectiva}

A recordação terá as suas raízes na subjectividade, mas só se torna possível por referência aos outros, ao que lhe é exterior e à sociedade ${ }^{3}$. A memória individual emerge como resultante de uma relação polarizada de diferentes memórias (pessoais, familiares, de grupo, etc.) radicada numa construção permanente ${ }^{4}$. A anamnese surge assim como experiência de subjectividade e como espaço para "a identidade do eu» 5 unificar os tempos sociais de participação do indivíduo.

Uma análise do processo histórico das reflexôes sobre a memória destaca a bipolarização entre uma fenomenologia da memória individual e uma sociologia da

\footnotetext{
${ }^{1}$ Um agradecimento à Teresa Cunha que com as suas leituras atentas, das diferentes versões, comentários e sugestóes, contribuiu para a forma do presente trabalho.

${ }^{2}$ Cf. Ricoeur, Paul - La Mémoire, L'Histoire, L'Oubli. Paris: Éditions du Seuil, 2000.

${ }^{3}$ Cf. HalbWaChS, Maurice - La Mémoire collective. Paris: Albin Michel, 1997.

${ }^{4}$ Cf. Catroga, Fernando - ob. cit., 2001, p. 16.

5 Idem, ibidem.
} 
memória colectiva ${ }^{6}$, expressão da atribuição da memória à vivência pessoal ou à sua dimensão social e colectiva. A «interiorização da alteridade» ${ }^{7}$ permite uma analogia entre estruturas do tempo subjectivo e a que confere sentido à vida colectiva ${ }^{8}$, estimulando a entificação da dimensão social e colectiva da memória, génese da «reflexão exterior» e integrada numa sociologia da memória colectiva ${ }^{9}$, de tradição durkheimiana, que foi consagrada por Maurice Halbwachs ${ }^{10}$ e cujas posiçôes viria a rever, em parte, no Mémoire collective ${ }^{11}$, considerando a memória social virtual como pano de fundo onde indivíduos e grupos constroem, respectivamente, as memórias individuais e colectivas, constituindo o reconhecimento de um papel activo do sujeito através da sua memória individual no processo de socialização e na modificação do que recebe por herança ${ }^{12}$. A memória individual torna-se dependente do papel desempenhado pelo indivíduo em cada grupo de pertença ${ }^{13}$.

\section{A memória social como prática do discurso}

Numa análise de histórias de vida conduzida por Gérard Namer ${ }^{14}$, a memória apresenta-se como uma narrativa organizada, um diálogo virtual que compreende a linguagem, o sistema de julgamento, as noções e categorias colectivas constrangido pela formalização do ritual, do conteúdo e tom da prática social do diálogo num momento e dum grupo num dado espaço. A memória como diálogo social formalizado, pronta a ser dita perante um público, que resulta de um diálogo interior prévio, dirigindo-se a um vago público futuro, e que se actualiza nas interacçôes sociais. A memória individual insere-se nos modelos culturais de diálogo da sociedade e grupos de pertença do indivíduo ${ }^{15}$.

Em situação de entrevista, de modo ocasional ou provocado, vai-se além da memória acessível do sujeito, tocam-se recordações isoladas, de que o sujeito fala a primeira vez. Trata-se da emergência de memórias escondidas, na medida em que podem corresponder a temas mais ou menos interditos e porque não são susceptíveis de serem preparadas no foro interior do sujeito por um diálogo social. Consiste numa

\footnotetext{
${ }^{6}$ CF. Ricoeur, Paul - ob. cit., 2000, pp. 112-163.

${ }^{7}$ Catroga, Fernando - ob. cit., 2001, p. 18.

${ }^{8}$ Idem, ibidem. É partindo desta analogia que Reinhart Koselleck radica a consciência histórica moderna na visão judaico-cristã do tempo. Veja-se KOSELLECK, Reinhart - Le futur passé: contribution à la sémantique des temps historiques. Paris: École des Hautes Etudes en Sciences Sociales, 1990.

${ }^{9}$ Cf. Ricoeur, Paul - ob. cit., 2000, pp. 112-163.

${ }^{10}$ Halbwachs, Maurice - Les cadres sociaux de la mémoire. Paris: Albin Michel, 1994 [1925].

${ }^{11}$ HalbWaCHS, Maurice - ob. cit., 1997.

${ }^{12}$ Cf. Catroga, Fernando - ob. cit., 2001, p. 20.

${ }^{13}$ Cf. NAMER, Gérard - ob. cit., 1987, p. 230.

${ }^{14}$ Cf. NAMER, Gérard - ob. cit., 1987. Veja-se ainda: NAMER, Gérard - Postface. In HalbWACHS, Maurice - ob. cit., 1994.

${ }^{15}$ Idem, ibidem, pp. 129-133.
} 
memória deslocada pelo tom em que seria falada, num contexto de memória abrangente ou regional.

A atenção a dispensar a fricções, contradições e aos diferentes interesses no interior de grupos e indivíduos leva a colocar o enfoque nos "processos e actores que intervêm no trabalho de constituição e de formalização das memórias» ${ }^{16}$, sublinhando a importância de memórias subterrâneas, "como parte integrante das culturas minoritárias e dominadas» ${ }^{17}$ que se contrapõem à memória oficial, num trabalho de subversão, no silêncio, irrompendo «em momentos de crise em sobressaltos bruscos e exarcebados» ${ }^{18}$. A memória entra em disputa, existindo conflito e competição entre memórias concorrentes. As memórias subterrâneas permanecem em estruturas de comunicação informais passando sem se fazerem notar pela sociedade. Surge assim espaço, nas lembranças, para zonas de sombra, silêncios e «não-ditos». A «fronteira entre o dizível e o indizível, o confessável e o inconfessável» ${ }^{19}$ separa as memórias subterrâneas das memórias oficiais.

A memória como sustentáculo da coesão interna do grupo, oferece pontos de referência resultantes de um trabalho profissional de enquadramento que resulta na produção de discursos e objectos materiais que, colocando o enfoque nas memórias individuais, permitirá destacar os limites desse trabalho e realizar uma aproximação ao papel do indivíduo no controlo dos desfasamentos entre a imagem oficial e as suas lembranças pessoais ${ }^{20}$.

O trabalho de esquecimento é fundamental na memória colectiva. A mudança de estrutura de um grupo estará na base de alterações na sua memória, transformando a recordação em esquecimento ${ }^{21}$. O esquecimento do grupo obedece a uma finalidade, o interesse do grupo - uma política de esquecimento ${ }^{22}$, transparecendo a natureza selectiva do passado. A memória é o ponto de chegada da interacção entre esquecimento e conservação. A restituição integral do passado é uma impossibilidade ${ }^{23}$. Existirão traços que serão conservados e outros esquecidos, conservar sem escolher não será um trabalho de memória ${ }^{24}$. A recordação tende a esquecer-se do esquecido ${ }^{25}$,

\footnotetext{
${ }^{16}$ Vejam-se: POLLAK, Michael - Memória, Esquecimento, Silêncio. In Estudos Históricos. Rio de Janeiro, vol. 2, n.o 3, 1989, p. 4. [Consult. 2006-01-21]. Disponível na WWW: <URL: http://www.cpdoc.fgv.br/ revista/arq/43.pdf>. POLLAK, Michael - Memória e Identidade Social. In Estudos Históricos. Rio de Janeiro, vol. 5, n. ${ }^{\circ}$ 10, 1992, pp. 200-212. [Consult. 2006-01-21]. Disponível na WWW: <URL: http://www. cpdoc.fgv.br/revista/arq/104.pdf>. POLLAK, Michael - L'Expérience Concentrationnaire. Essai sur le maintien de l'identité sociale. Paris: Editions Métailié, 2000.

17 Idem, ibidem.

18 Idem, ibidem.

19 Idem, ibidem.

${ }^{20}$ Idem, ibidem.

${ }^{21}$ Cf. HalbWachs, Maurice - ob. cit., 1997.

${ }^{22}$ Cf. NAMER, Gérard - ob. cit., 1987.

23 Cf. Todorov, Tzvetan - Les Abus de la Mémoire. Paris: Arléa, 1995, p. 14.

${ }^{24}$ Idem, ibidem.

${ }^{25}$ Cf. Catroga, Fernando - ob. cit., 2001.
} 
recordar será seleccionar e esquecer mas será também resgatar e terá sempre por base um trabalho da memória ${ }^{26}$.

\section{Memória, História e Historiografia}

A distinção entre História e Memória é inquestionável e, de resto, trata-se de um assunto amplamente documentado ${ }^{27}$. O meu ensejo é assinalar características comuns entre a memória e o trabalho historiográfico, nomeadamente, ao nível da selecção, do finalismo ao presentismo, na verosimilhança, na representação, numa perspectiva não contínua do tempo e na relação entre o sujeito e o seu objecto ${ }^{28}$.

A historiografia é, assim, também ela, produtora de memórias e tradições. Se por um lado, a narrativa histórica se centra na denominação, se preocupa com os sujeitos, a memória dá subida atenção à descrição, à qualificação dos acontecimentos e ao sentido dos acontecimentos. Se aspiramos a uma verdade de adequação, será necessário confrontar os testemunhos orais com outras fontes mas a memória acolhe mais facilmente a experiência física e espiritual, incita-nos a matizar e a complexificar os nossos julgamentos sem os condenar a um relativismo integral. A memória compensa a dificuldade em atingir uma verdade de adequação por uma maior verdade de desvendamento, de revelação, revelando o sentido dos acontecimentos com tanta eficácia como as formulações abstractas dos historiadores. As duas diligências são complementares, se pretendemos conhecer o interior das experiências dos defensores de ideologias opostas, deveremos ouvir as narrações memorialísticas; se desejamos conhecer o valor das suas posições, as consequências práticas de uma e de outra, a relação entre palavras e actos, deveremos debruçar-nos sobre o trabalho dos historiadores. A verdade de adequação que caracteriza a história e verdade de desvendamento que marca a memória complementam-se e completam-se ${ }^{29}$.

${ }^{26}$ Cf. Ricoeur, Paul - ob. cit., 2000, pp. 82-111. Não cabe aqui analisar o trabalho da memória, enquanto linguagem pública, colectiva e instituinte, patente nas comemorações, espaço de luta de memórias concorrentes. A esse propósito veja-se: CATROGA, Fernando - ob. cit., 2001; CATROGA, Fernando - Ritualizaçōes da História. In Torgal, Luís Reis; Mendes, José Maria Amado; Catroga, Fernando - História da História em Portugal. Séculos XIX-XX. Lisboa: Círculo de Leitores, 1996; Mendes, José Manuel de Oliveira - ob. cit., 2003, pp. 59. José Manuel Mendes mobiliza no seu estudo as análises de Barry Schwartz sobre as diferentes versões de Abraham Lincoln de acordo com a época histórica; Mona Ozouf descreve a utilização da festa revolucionária ao serviço da memória. A comemoração integra o programa revolucionário - tratava-se de «alimentar» a recordação da revolução. Veja-se: Ozouf, Mona - La Fête Révolutionnaire. Paris: Gallimard, 1976.

${ }^{27}$ É o caso de autores como Lucien Febvre, Henri-Irenée Marrou, Pierre Nora e Krzystof Pomian. Cf. Catroga, Fernando - ob. cit., 2001, p. 25. Vejam-se: Febvre, Lucien - Combates pela História. Lisboa: Livros Horizonte, 1977. MARROU, Henri-Irenée - Do conhecimento Histórico. Lisboa: Editorial Aster, 1974. NORA, Pierre et al. - ob. cit., 1984. POMIAN, Krzystof - Sur l'histoire. Paris: Gallimard, 1999. Ainda sobre o entendimento desta relação em Pierre Nora veja-se: RICOEUR, Paul - ob. cit., 2000, pp. 522-535. 2000.

${ }^{28}$ Cf. CATroga, Fernando - ob. cit., 2001, pp. 40-50. Veja-se a este propósito: RiCOEur, Paul - ob. cit.,

${ }^{29}$ Cf. Todorov, Tzvetan - La mémoire devant l'histoire. In Terrain 25 (1995) 101-112. 


\section{Memória, cultura e ideologia}

\section{A problemática da cultura}

A natureza simbólica da memória ${ }^{30}$ justifica a atenção a dedicar aos processos simbólicos, para a compreensão das dinâmicas relacionadas com as construções das memórias individuais, colectivas e sociais, sustentando que os símbolos, o processo de simbolização e os produtos simbólicos são o resultado da interação ${ }^{31}$.

Adopto a concepção geertziana de cultura ${ }^{32}$ conceito "essencialmente semiótico» ${ }^{33}$ considerando que o "homem é um animal amarrado a teias de significados que ele mesmo teceu» ${ }^{34}$, em que a cultura são as teias e a sua análise, percebida como "uma ciência interpretativa, à procura do significado» ${ }^{35}$, de algo que se apresenta e pode ser lido como um texto, "uma hierarquia estratificada de estruturas significantes» ${ }^{36}$, socialmente estabelecido e contextualizado. No estudo da cultura os significantes são actos simbólicos e o objectivo é a "análise do discurso social» ${ }^{37}$, no ensejo de desvendar «as estruturas conceptuais que informam os actos dos sujeitos, o dito no discurso social» 38 .

$\mathrm{O}$ indivíduo tem um papel criativo nas representações colectivas, impondo-se a necessidade de estar atento à existência de alternativas aos processos de produção cultural dominante ${ }^{39}$ incorporando o contigente e o aleatório na análise dos processos culturais, integrando a resistência cultural e a produção de contramemórias como possíveis alternativas, tanto mais que as culturas dominantes parecem constranger mais na acção e luta política ${ }^{40}$ do que ao nível do pensamento e ideologia ${ }^{41}$.

Neste sentido, na linha de Bernard Lepetit ${ }^{42}$, a formação social, analisada como uma categoria de prática social, deve ser encarada como construtora das suas próprias

${ }^{30}$ Cf. NAMER, Gérard - ob. cit., 1987, pp. 58-62.

${ }^{31}$ Cf. Mendes, José Manuel de Oliveira - ob. cit., 2003, p. 60.

32 Cf. GeERTZ, Clifford - A interpretação das culturas. Rio de Janeiro: Zahar Editores, 1978, pp. 13-41.

33 Idem, ibidem, p. 15.

${ }^{34}$ Idem, ibidem.

35 Idem, ibidem.

${ }^{36}$ Idem, ibidem, p. 17.

${ }^{37}$ Idem, ibidem, p. 36.

${ }^{38}$ Idem, ibidem, p. 37.

${ }^{39}$ Cf. SAID, Edward - Culture and Imperialism. London: Vintage, 1995.

${ }^{40}$ Cf. SCOTT, James - Dominance and the Arts of Resistance. Hidden Transcripts. New Haven: Yale University Press, 1990.

${ }^{41}$ Cf. Mendes, José Manuel de Oliveira - ob. cit., 2003, p. 62.

${ }^{42}$ Cf. LePeTit, Bernard - Une autre histoire sociale. In Correspondances. Bulletin cientifiques de l'IMRC, 1996. [Consult. 2006-02-18] Disponível em URL: http://www.irmcmaghreb.org/corres/textes/ lepetit.htm. Trata-se de uma transcrição da comunicação oral realizada por Bernard Lepetit e que constituiu a sua intervenção nas jornadas Pratiques du métier d'historien (1996), organizado em Cartago, pelo IMRC (Institut de Recherche sur le Maghreb Contemporain) e pela Academia Tunisina, com o patrocínio da Maison des Sciences de l'Homme e da École des hautes Études en Sciences Sociales, e cujo texto o autor nunca chegou a rever pois foi surpreendido, prematuramente, pela morte duas semanas depois. 
referências, instituições, identidades sociais, laços sociais. O enfoque na acção valoriza a descrição em detrimento da explicação, a compreensão do mundo passa por uma descrição fina dos fenómenos, permitindo responder à questão do como, articulada com o recurso às escalas. A descrição permite captar a acção na sua configuração temporal e espacial, possibilita a resposta à questão porquê, na medida que reporta as acções aos contextos de sentido na qual elas têm lugar. Na ordem das categorias temporais ter em conta a acção e os actores conduzirá à valorização da curta duração, do acontecimento, da acção situada. É numa série de acções situadas, na inter-relação e na interacção que se constroem as regras e as normas. Nesta ordem prestar atenção à acção não implica necessariamente a desvalorização da longa duração. A recentração na acção coloca no presente toda a carga temporal da história e leva a encarar com seriedade os modelos temporais dos actores ${ }^{43}$.

\section{O papel da ideologia - os dilemas ideológicos}

A ideologia ${ }^{44}$ na acção dos «empresários da memória» — mediadores e produtores de memórias colectivas - constitui um eixo central. Não caberá aqui uma análise cuidada de um conceito tão elusivo ${ }^{45}$, sublinho, contudo, que a ideologia fornece recursos para a «negociação do sentido e da produção de consensos, tradições e memórias» ${ }^{46}$. Procurando salientar que as ideologias são portadoras de contradições e dilemas, parto das propostas de Boaventura Sousa Santos ${ }^{47}$, considerando uma concepção retórica do conhecimento, sustentando que as ideologias produzem lugares comuns e senso comum, constituindo-se em premissas de argumentação, tornando-se temporariamente em "factos ou verdades» ${ }^{48}$, que «são objectos com aceitação suficientemente intensa para não exigir reforço pela argumentação» ${ }^{49}$ ou podem

43 Cf. LepetiT, Bernard - ob. cit., 1996.

${ }^{44}$ A palavra ideologia terá tido uma utilização positiva quando um grupo de pensadores se identificava como idéologues, uma escola filosófica francesa setecentista, que perfilhava uma filosofia semântica - com a pretensão de radicar a filosofia nas ideias afastando-a das coisas e da realidade. Opositores de Napoleão e do Império - de que destaco Destutt de Tracy, eram tratados pejorativamente por idéologues, estando assim na génese da conotação negativa, que remonta a Napoleão. Cf. RiCOEUR, Paul - ob. cit., 1991, pp. 69-70. Uma análise mais detalhada pode encontrar-se em: THOMPSON, John B. - ob. cit., 1995, pp. 44-49.

${ }^{45}$ Cf. Ricoeur, Paul - Ideologia e Utopia. Lisboa: Edições 70, 1991. Sobre o conceito de ideologia vejam-se ainda a título de exemplo: LARRAIN, Jorge - The Concept of Ideology. Londres: Hutchinson, 1979. LARRAIN, Jorge - Ideology and Cultural Identity. Modernity and the Third World Presence. Cambridge: Polity Press, 1994. Thompson, John B. - Ideologia e cultura moderna: teoria social na era dos meios de massa. Petrópolis: Vozes, 1995.

${ }^{46}$ Mendes, José Manuel de Oliveira - ob. cit., 2003, p. 67.

${ }^{47}$ Cf. SANTOS, Boaventura de Sousa - A crítica da razão indolente. Contra o desperdício da Experiência. Para um novo senso comum: A ciência, o direito e a política na transição paradigmática. Volume I. Porto: Ediçôes Afrontamento, 2002, p. 93.

${ }^{48}$ Idem, ibidem.

49 Idem, ibidem. 
transformar-se em argumentos que servem a «construção, reconstrução ou abandono de memórias colectivas e sistemas simbólicos» ${ }^{50}$.

As ideologias são produtoras de lugares-comuns, de senso comum ${ }^{51}$. A ideologia não como um sistema completo e unificado de crenças mas como portadora de contradições e temas opostos. Sem temas contrários os indivíduos não conseguiriam resolver ou decifrar problemas dos seus mundos sociais ou experienciar dilemas e sem isso pensá-los seria impossível ${ }^{52}$.

Os temas contrários do senso comum - que possui natureza dilemática, permitem aos indivíduos pensar as suas vidas ${ }^{53}$, capacitando-os a discutir e resolver situações da vida quotidiana. Os dilemas de uma pessoa não são os de outra ${ }^{54}$. Os dilemas são dilemas sociais pois referem-se a imagens sociais ${ }^{55}$. O senso comum possui vocabulário que expressa os temas conflituantes, as palavras expressam avaliações morais, termos frequentemente expressos em oposiçôes anti-téticas que facilitam a oposição de julgamentos morais ${ }^{56}$.

Os temas contrários que fornecem as sementes da argumentação e do pensamento estão intimamente ligados, a reflexão sobre um dilema, conduz a sopesar prós e contras como se de uma argumentação se tratasse. A argumentação social pode ser vista como modelo para o pensamento social ${ }^{57}$. Se pensamento e argumentação estão ligados então a capacidade para usar a retórica é universal. Em qualquer sociedade se pode esperar que as pessoas se auto-justifiquem e ao criticarem as visões de outros, elas utilizaram a retórica da argumentação ${ }^{58}$. Os aspectos dilemáticos podem ser explícitos ou implícitos, dependendo em parte dos processos sociais e das práticas discursivas existentes nas comunidades de pertença ${ }^{59}$. Neste enfoque faz sentido a distinção entre

${ }^{50}$ Mendes, José Manuel de Oliveira - ob. cit., 2003, p. 67. Reforço, na linha de José Manuel Mendes, a importância de estar atento à distinção entre registos públicos e ocultos - das elites e de dominados, onde a resistência à dominação é constante e irrompe de múltiplas formas, nomeadamente pela indignação, e, por outro lado, a desconstrução da concepção homogénea dos subordinados.

${ }^{51}$ Cf. Billig, Michael et al. - Ideological Dilemmas. A Social Psychology of Everyday Thinking. London: Sage, 1988. Billig, Michael - Methodology and Scholarship in Understanding Ideological Explanation. In ANTAKI, Charles org. - Analysing Everyday Explanation. A Casecook of Methods. London: Sage, 1988. BILlig, Michael - Collective Memory, Ideology and the British Family. In MiddLETON, David; Edwards, Derek org. - Collective Remembering. London: Sage, 1990. BILLIG, Michael - Ideology and Opinions. Studies in Rhetorical Psychology. London: Sage, 1991. Utilizei, em particular, para a minha abordagem sintética, o primeiro dos textos aqui referido de Michael Billig (1988) e a reflexão analítica de José Manuel Mendes que, aliás, se revelou essencial.

${ }^{52}$ Cf. Billig, Michael et al. - Ideological [...], 1988, p. 2.

53 Idem, ibidem, p. 9.

${ }^{54}$ Idem, ibidem, p. 11.

55 Idem, ibidem, p. 14.

${ }^{56}$ Idem, ibidem, pp. 16-17.

57 Idem, ibidem, p. 17.

${ }^{58}$ Idem, ibidem, p. 18.

59 Idem, ibidem, pp. 20-24. 
ideologia vivida e ideologia intelectual, sendo a primeira identificada com a forma de vida de uma sociedade e a segunda, um sistema integrado de ideias ${ }^{60}$.

\section{A Escola do Magistério Primário de Coimbra (1942-1989). Entre Ideologia, Memória e História.}

Quero sublinhar como ponto prévio por um lado, a percepção da investigação científica como um processo interactivo moldado pela minha história pessoal, biografia, género e classe social de pertença, bem como pelas das pessoas do estudo e, por outro lado, um entendimento dos dados de investigação como selecções da realidade, sem contudo, contradizer o conceito de objectividade ou o esforço que desenvolvo para aumentar essa possibilidade.

Enquadrado numa abordagem de investigação qualitativa centrei a atenção no estudo dos discursos dos actores sociais, percebidos como acção, privilegiando como técnicas de recolha de dados, a análise documental de uma publicação periódica e a entrevista, colocando os actores sociais em discurso directo. Para a análise e tratamento de dados mobilizei as propostas da teoria ancorada (Grounded Theory) articulada com a análise crítica do discurso, na proposta de Teun Van Dijk.

A análise documental centrou-se no jornal Rumo, periódico da responsabilidade dos alunos da Escola do Magistério Primário de Coimbra que asseguravam a respectiva direcção, redacção e administração. A publicação conheceu dois períodos de existência, o primeiro, entre 21 de Janeiro de 1949 e 15 de Julho de 1957 e, um segundo, entre 1 de Dezembro de 1959 e Fevereiro de 1969. O hiato ficou a dever-se às dificuldades criadas pela mudança de instalaçôes da escola. $\mathrm{O}$ jornal teve quatro subtítulos - Rumo:

i) Jornal dos alunos da Escola do Magistério Primário de Coimbra;

ii) Quinzenário dos alunos da Escola do Magistério Primário de Coimbra;

iii) Mensário dos alunos da Escola do Magistério Primário de Coimbra;

iv) Órgão dos alunos da Escola do Magistério Primário de Coimbra.

Constituiu um estudo exaustivo, tendo como unidade de análise a notícia e os diferentes artigos que compõem o jornal. A abordagem orientou-se para a problemática ideológica e simbólica dos vários discursos, estando atento à forma como os actores sociais reproduzem o discurso oficial ao nível local e institucional, pretendendo detectar temas e recursos mobilizados na construção da argumentação. Procurei identificar os níveis mobilizados na argumentação — do local ao internacional, entre o micro e o macro, destacando objectivos propostos, os aliados e os adversários, e a opacidade em relação a certos posicionamentos. Resultou numa construção da ideologia e representações no Estado Novo organizada em cinco conceitos chave: a Moral Católica, a «Educação Nacional», o Quotidiano, a Política e a Mulher.

No âmbito da Moral Católica irrompeu uma concepção de pessoa humana, vista e percebida como imagem e semelhança de Deus e as normas de conduta a seguir. Destaco o papel atribuído à igreja, o código de conduta, as representaçôes sociais e a acção das missões católicas.

${ }^{60}$ Idem, ibidem, pp. 25-32. 
A análise do conceito de «Educação Nacional» centrou-se sobre a política educativa, nomeadamente o combate ao analfabetismo e o Plano de Educação Popular coincidindo com uma importante fase de mobilização da formação social portuguesa. A categoria ensino surge caracterizada nas subcategorias de ensino normal, no binómio educação versus instrução, a educação integral, a coeducação e as relações entre a escola e a família. Da explicitação do conceito de "Educação Nacional» surgem ainda as categorias de professor e criança caracterizadas pelo papel e imagem dos actores sociais. A categoria escola é assinalada enquanto espaço educativo e de inculcação ideológica, num momento vital da existência da Escola do Magistério Primário de Coimbra, a inauguração do seu edifício construído de raiz.

Os discursos sobre o quotidiano centraram-se em questóes como o clima relacional, as festas, as cerimónias, os órgáos institucionais e organizações existentes. No âmbito das organizações surgiram a Liga Escolar Católica, as Conferências de S. Vicente de Paulo — a feminina e a masculina, S. João Maria de la Salle — e a Liga Intensificadora de Acção Missionária.

O conceito de Política operacionalizou-se em quatro categorias: o Estado, o nacionalismo corporativo, Portugal e o ultramar e as relaçóes internacionais. Numa abordagem sincrónica em 1962, coloquei o enfoque dos discursos produzidos sobre Portugal e o ultramar e as relaçóes internacionais. Numa perspectiva diacrónica, orientei a análise para os posicionamentos face à família.

A aproximação aos discursos sobre a Mulher foi feita em termos comparativos, escolhendo dois momentos diferentes, em que me detive sobre o comportamento social da mulher, as relaçóes com o género masculino, o seu papel e expectativas no lar e no mercado de trabalho. Dediquei especial atenção aos discursos sobre a mulher enquanto professora do ensino primário.

A importância de complementar um "discurso oficial» patente no jornal Rumo e a possibilidade de ouvir os actores sociais em discurso directo sobre todo o tempo de existência da instituição, incluindo os períodos como as experiências pedagógicas, e a normalização, atravessando épocas historicamente marcantes e de intenso confronto ideológico, espaços de conflito e competição de memórias concorrentes, abriram espaço para o recurso à entrevista e à mobilização da memória dos actores sociais.

$\mathrm{O}$ recurso às vozes dos actores sociais permitiu romper com a ideia do carácter hegemónico dos discursos estado novistas. No que se refere à concepção de professor, atente-se nas palavras de Francisco Quaresma, professor da Escola na década de sessenta, constrói uma crítica do "espírito de missão" conotando-a com uma época. Começa por considerar que esse "espírito de missão» já na época em que foi professor da Escola do Magistério Primário de Coimbra era um «slogan» e diz mesmo que «já não se acreditava muito nesse espírito de missão». Argumenta que a associação entre professor e sacerdócio esbarra em dois obstáculos, por um lado, a sua desadequação à década de sessenta e, por outro, tratava-se de uma postura desadequada ao nível etário dos alunos-mestres e das alunas-mestras. Identifica uma adversária, Julieta Carvalho, invectivando contra as suas posições e postura:

"Luís Mota: Sr. Dr., continuando a nossa conversa, como é que vê o papel do professor, como é que via, nessa altura, na Escola do Magistério, o papel do professor. Também entendia, ou entende, o professor como um espírito de missão? (//)

Francisco Quaresma: (//) (eh) Bom, isso (//) 
Luís Mota: (//) Ou, como é que vê esse espírito de missão?

Francisco Quaresma: Bom, isso já na altura era um slogan que, (eh) já não se acreditava muito nesse espírito de missão. É claro, o professor é um profissional (eh) e o espírito de missão tem que existir mas temperado por outros espíritos, não é, (eh) aquela coisa do sacerdócio, do professor ser o sacerdócio pois, já na altura os sacerdotes andavam pelas boates e tal, e o professor é que seria o sacerdócio, não! (hã), o professor tem de ser um educador, tem que ser um formador, tem que ser um homem que dê um exemplo, não é, mas também não pode agora armar em sacerdote e estar a querer aquilo que uma determinada (ah) época ou uma determinada (eh) idade, até pode compreender. Sim porque ninguém, no mundo, com uma idade de dezassete ou dezoito anos compreendia certas reivindicações de ordem moral, (ah) como por exemplo fazia a D. Julieta. Sim, essa Sr. ${ }^{a}$ e tal, que com muito boa intenção, sem dúvida, ela era uma pessoa (eh) superior nesse aspecto, mas claro, queria que os alunos alinhassem já por uma idade avançada, (ah) não podia ser, não é. Contrariava um bocado os namoricos, elas andavam aí a esconder-se pelos cantos com os namoricos para que a D. Julieta não visse, é claro, já era um exagero, não é [a sorrir]. Ora, não é essa verdadeiramente a missão do professor. Ela fazia aquilo por bem, não é, mas era um bem que no fim de contas acabava por nem ser bem, não é. Ora, o professor tem que ser um educador, um formador (eh) tem que ser compreensivo em relação a uma determinada idade, e ter um determinado temperamento porque nem todos os alunos têm o mesmo temperamento, não é, (eh) se há uns mais dóceis há outros que não são, (eh) se há uns alunos têm mais propensão até para se desviar de determinadas normas (ah) outros não terão, (ah) de maneira que o professor tem que ser um orientador fundamentalmente mas nunca um impositor, não é».

Quando aborda a sua formação e desempenho profissional, refere a importância da bibliografia francófona - janela de oportunidade, para uma formação autodidacta:

«Francisco Quaresma: [...] E eu fazia-o muito frequentemente porque tive a facilidade de arranjar uns livros franceses, não é, ah e belgas, que já estavam a ver as coisas de uma maneira diferente, lia aquilo e fundamentalmente o que me interessava aqui era que os alunos saíssem mentalizados daqui, com esta ideia central, que a criança era um ser vivo que estava ali e que era preciso merecer uma atenção muito especial e que, antes de castigar ou antes de reprimir, $[\ldots]$ ».

Partindo da situação de entrevista procurei restituir a voz aos actores sociais, explicitando a descrição e sentido que os seus discursos dão aos acontecimentos e momentos vividos na Escola do Magistério Primário de Coimbra e como qualificam o papel que a instituição desempenhou na sua vida e nas realidades local e nacional, no sentido do passado e prospectivo, ensaiando ir além da abordagem meramente institucional e mobilizando história e memória, num enfoque de complementaridade. Nesta perspectiva e com a disciplina de Teoria e Dialéctica da História em análise, criada durante as experiências pedagógicas, atentemos no discurso de Joaquim Viegas, director da Escola, criador da disciplina, autor do programa e seu principal impulsionador: 
«Joaquim Viegas: Exacto.

Luís Mota: tinha si, poderia ter sido um erro, ou um excesso. Como é que, como é que vê essa situação, era essencial para o processo de desconstrução,

Joaquim Viegas: Pois.

Luís Mota: daquilo que existia e essencial para essa consciencialização política, atendendo ao contexto da época ou é essencial, tout-court, se me permite (.)

Joaquim Viegas: Por acaso quem, quem promoveu a disciplina fui eu e quem fez o programa fui eu e, portanto, está a falar com a pessoa que percebe qual era a intenção da, da, da disciplina, embora sempre com a participação do director-geral, tivemos, a esse nível, evidentemente, que tivemos uma protecção especial, um, um incentivo fundamental da, da direcção, da direcção-geral, do, do Rogério Fernandes e do (//) Salvado Sampaio,

Luís Mota: (//) Salvado Sampaio.

Joaquim Viegas: que era, que era o director de serviço, eram, eram, aliás, o clima era espantoso, não é, mas (ham) a disciplina parecia-me, exactamente na, naquela perspectiva de dar consciência política, não uma consciência política partidária, embora a Teoria e Dialéctica da História parecesse (eh) parecesse, como é que hei-de dizer, mono, ((sorri)) mono, mono-direccionada, se quisermos, mas na, na, na, na perspectiva que eu tinha era a necessidade de dar aos alunos, como disse à pouco, a, a possibilidade de conhecer a realidade, conhecer a História portuguesa no sentido das emancipa, digamos da, do, da, das aspiraçôes, da, da, da população mais pobre, se quisermos, da, da população oprimida socialmente e economicamente, os movimentos que foram sendo gerados e reprimidos no sentido da emancipação, portanto, era necessário que os, os professores percebessem isso, de forma a inserir a sua função nesse movimento, nesse movimento, não é, (ham) e era, era, era um pouco nesse sentido, da consciência política da função, da função do, do, do professor, não é, que deve ser um agente de emancipação, um agente de emancipação, deve corresponder às aspirações, deve fazer elevação da cultura, portanto, combater o analfabetismo e, por isso, o professor que nós pretendíamos formar não era um professor escolar, mas era um professor social, um professor que agia não só com as crianças mas também com, com os pais das crianças, com os avós das crianças, e portanto, deveria de certa forma ser um, um, um animador do desenvolvimento social, não é, portanto, a, aquela, aquela disciplina parecia fundamental, não é, evidentemente que eu, eu, eu sei, foi, foi a primeira a ser eliminada (//) logo e objecto, inclusivamente,

Luís Mota: (//) Sim, sim.

Joaquim Viegas: duma intervenção do, do Sottomayor Cardia, na televisão, uma coisa curiosa, quer dizer, sentiram tanto o peso daquela disciplina que me lembro do, do Sottomayor Cardia dizer que era uma disciplina estalinista, não é, bom achei, ri-me da, da, da expressão dele, não é, estalinista, havia ainda preconceitos muito grandes, havia muito medo da, da, da classe média intelectual se quisermos assim, quer dizer, havia muito medo, a, como aliás se verificou depois, quando, quando os, os próprios políticos acabaram por, por se associar ao, à, à CIA, aos americanos, nós sabemos o papel que a CIA (//) desempenhou na, na contra-revolução,

Luís Mota: (//) Desempenhou.

Joaquim Viegas: ou naquilo que depois o próprio Car, o Sottomayor Cardia falou na normalização, ((ri)) na normalização, não é, e hoje é curioso ver o, o, o Mário Soares ser tão anti-americano ou pelo menos, anti-americano no sentido da política 
americana, não é, portanto, a história também é feita disto, dessas, dessas, dessa, é, é pendular, vai-se para a frente, vem-se para trás, portanto, não é um, não é um percurso (//) linear, não é, e,

Luís Mota: (//) Linear.

Joaquim Viegas: e, e, portanto, naquele altura nós estávamos, digamos, o pêndulo estava todo voltado à esquerda, isso, isso é óbvio, não é, estava todo voltado à esquerda e a cadeira, era exactamente isso, falava na, na vertente científica, na vertente política, na, havia uma terceira vertente, que era a vertente cultural, não é, [...]».

A argumentação de Joaquim Viegas pode sintetizar-se em três pontos:

i. A justificação histórica e ideológica da disciplina.

ii. A disciplina e o combate político-ideológico no plano nacional e internacional

— os adversários de ontem são os de hoje.

iii. Uma leitura histórica e da História: a metáfora do pêndulo.

Constrói a argumentação de justificação da disciplina assente na sua importância para a formação dos professores e em face do professor que se pretendia formar. O objectivo primeiro era dotar o futuro professor de consciência política - recusa explícita da formação política partidária, ainda que possa parecer uma disciplina unidireccionada - isto é, no intuito de que este conheça o sentido da História no que traduz de aspirações e libertação dos mais pobres e oprimidos, do ponto de vista social e económico. A tomada de consciência deveria conduzir o professor a transformar-se em "agente de emancipação", o professor social.

A retórica deixa de se centrar na disciplina para passar ao plano nacional, transformando-se em combate político-ideológico quando dialoga com Mário Sottomayor Cardia, que considerou a disciplina estalinista, o que Joaquim Viegas considerou ser fruto do preconceito e receio da "classe média intelectual». Esta posição de Cardia, tem para Viegas, paralelo, na política internacional, com os políticos a associarem-se à Central Intelligence Agency (CIA), sugerindo o papel desta organização na contra- revolução, que em Educação teve a sua tradução - baptizada e conduzida por Sottomayor Cardia - na normalização. Neste discurso os adversários de ontem são os de hoje, daí que Joaquim Viegas, deixe cair o desabafo: «e hoje é curioso ver o Mário Soares ser tão anti-americano ou, pelo menos, anti-americano no sentido da política americana».

Adoptar uma concepção de História, na medida em que a considera cíclica e não linear, mas cíclica no sentido da distribuição e equilíbrio de forças face ao poder e, simultaneamente, caracteriza o momento da História de Portugal que criou condições para as experiências pedagógicas e, em particular, para o aparecimento da disciplina de Teoria e Dialéctica da História, reconduzindo assim a sua argumentação dos planos internacional e nacional de novo à disciplina, analisando as suas diferentes vertentes.

A análise das memórias dos actores sociais centra-se, também, nos posicionamentos pessoais, dilemas ideológicos e memórias concorrentes face às vivências na Escola do Magistério Primário de Coimbra e nas questôes que vão desde a concepção de professor às perspectivas que os actores sociais guardam da formação, aos planos de estudo e avaliação. Os dilemas ideológicos pessoais podem ilustrar-se com o discurso de Marta Santos que começa por tomar posição: no plano de estudos das Experiências houve coisas "com as quais eu não concordei», porque «exageradas» e «datadas». 
Discordância, pura e simples para, em diálogo consigo própria, matizar com um não concordei «entre aspas», encerrando com a necessidade da discordância ser clarificada e aprofundada:

«Marta Santos: [...] (ham) Agora, (eh) houve também coisas (eh) no plano de estudos do período revolucionário, que eu, com as quais eu não concordei e que achei (eh) achei, (eh) exageradas, achei datadas, por exemplo, como é o tal caso da, daquela disciplina que eu agora não me lembro como é que era chamada (.)

LM: Teoria e Dialéctica da História.

Marta Santos: Exactamente, não é, pronto, isso, "não concordo" entre aspas, eu vou explicar porque é não, porque é que não, não concordei, porque é que achei que (eh) (.) vou explicar melhor porque eu não, não, se calhar não é bem não concordei, é assim, para uma (eh) instituição que tinha vivido com a OPAN ss, permanentemente sido inculcada aquela organização, sem mais nenhuma cultura política de nenhuma natureza, eu acho que era importante ser introduzido, ter sido introduzido uma cadeira de cultura política, sinceramente, agora não tinha que ser uma cadeira de cultura política (eh) marxista, mas também não fez mal, eu acho que não, não ((ri)) não foi nenhuma, não foi nenhum, não foi nenhum vírus, não é, agora, a minha ideia, até também possivelmente aqui porque eu sou, uma das minhas áreas de especialidade é a questão, é a questão da, dos currículos, (hem), é que estas, estas áreas, (eh) são áreas de circunstância, estas disciplinas são disciplinas de circunstância naquele momento (//) responde aquele período.

LM: (//) Ao momento histórico, não é.

Marta Santos: Não, naquele, para aquele período estaria ajustado, estávamos no período das dinamizações culturais, era o predo, era o dominante, pronto, acabou, não fez mal a quem teve a cadeira em si mesma, mas era alguma coisa que se via desde logo ou desde muito cedo que estaria condenada a desaparecer. O que vei, agora, a questão é esta, essas disciplinas tinham uma, um tempo, pronto, (ah) e o que veio a seguir, eu já não lembro o que é que foi distribuído, são coisas, são disciplinas académicas (.)

LM: Logo a seguir veio Introdução à Política.

Marta Santos: Pois, que é uma coisa que, pois, está bem.

LM: Que é igual ao Secundário.

Marta Santos: Que é igual ao Secundário. (.)

LM: E depois não veio nada.

Marta Santos: E depois não veio nada isso aí é que eu acho que está mal, isso aí é que eu acho que está muito mal, não é. Vir igual ao Secundário (ahg) já era uma situação que talvez de, porque esta gente, há mas também eles entravam com o $5^{\circ}$ ano, mas eu acho que a formação política, mínima, mas uma formação política consistente é importante na formação profissional, é, é importante, é preciso que aconteça. Não ter nada é muito mais grave do que ter tido Introdução ao, ao Marxismo, isso eu não tenha dúvida absolutamente nenhuma».

De um modo geral os entrevistados mobilizavam uma leitura da história, reactivando memórias e acontecimentos a que conferiam carácter fundacional, socorrendo-se de uma experiência vivida que destacavam como única e sinalizando aliados e adversários 
— os comunistas, os fascistas, a extrema-esquerda —, para legitimarem os seus posicionamentos.

Atentemos em duas leituras, de alunos-mestres, sobre o período das experiências pedagógicas e da normalização, no que se refere às tensões político-ideológicas. $\mathrm{Na}$ análise das relaçôes entre alunos-mestres e alunas-mestras, Óscar Nunes data da normalização as tensões político-ideológicas e avança com o exemplo da Associação de Estudantes. Só com a normalização surge «uma relação diferente» e uma certa crispação político-ideológica está na origem de duas listas. As transformaçōes que ocorrem nas escolas têm origem em alterações e mudanças no equilíbrio de forças políticas a nível nacional, e mostra claramente como os diferentes actores mobilizam temas locais e nacionais nos seus discursos:

«Óscar Nunes: [...] e eu recordo-me que por exemplo nesse segundo ano, no primeiro ano nós tínhamos uma Associação de Estudantes, que eu nem me lembro como é que foi constituída, mas penso que foi um bocado do género, quem é que quer e era o pessoal das turmas e as turmas escolhiam, (ah) ficas tu e tal, e a coisa era assim, no segundo ano e depois desta situação toda de mudança, passa a haver entre nós uma, uma relação diferente, (eh) a Associação de Estudantes, houve duas listas, logo, eu estava numa com o Pedro, com o Trincão, com essa malta, o Zé Maria, não sei quê, o Mário estava noutra, com o Aires, com essa malta e (hã, hã), estavam noutra, (hem) depois, e no terceiro ano isso volta a acontecer, no segundo ano, perdemos nós por uns trinta votos e no segundo, no outro ano, ganhámos por uns vinte votos, porque jogava-se ali muito na altura, para conseguir ganhar, nas regentes, como as ex-regentes era pessoal mais velho e pessoal do ponto de vista político, digamos, mais conservador, deram a vitória, no primeiro ano, à lista, digamos, se quisermos politicamente, menos, mais à direita e nós, quando percebemos isso fizemos a campanha, no ano a seguir, eu lembro-me de ir de bicicleta mais uns colegas a Montemor, porque havia uma série delas lá, fazer uma festa e lanchar com elas e tal, porque, ((a rir)) porque era aí que se jogava, porque nos estudantes era equilibrado, (ah) e inclusivamente nos estudantes no terceiro ano, essa lista é, cá está os factores políticos intervêm aí, essa segunda lista perde também porque nós conseguimos identificá-los com um colega nosso que tinha sido expulso da Escola por ser informador da PIDE em 74, que era o Manuel, que depois disso teve problemas de outro tipo (//) (hein) ((sorrindo)), pronto,

Luís Mota: (//) O marido da Manuela.

Óscar Nunes: e que foi readmitido já na fase do Falcão e já cá estamos nós a dizer, isto é outra vez o regresso do e não sei quê, e conseguimos que ele pusesse um dia o autocolante da outra lista e a partir daí eles perderam porque, mesmo o pessoal mais coiso como não, (eh) pá aquela coisa, estávamos em 76-77, o 25 de Abril tinha sido há três anos, um gajo ter estado ligado, informador da PIDE, ainda por cima era um gajo com actividade na Escola estava já, era um tipo reconhecido na rádio e tal, então e o gajo tinha actividade, dava-se bem com toda a gente e andava a fazer queixa dos colegas, isso não era bem visto, nada, e então ele perde, a lista perdeu quando nós percebemos que se jogava nas regentes e quando nós o colámos a eles à lista, e portanto, mas aqui mostra o quê, para dizer o quê, que há aqui factores claramente políticos já, (eh) na relação entre os estudantes, (eh) e portanto, nós a partir daí, desse segundo ano, e isto notou-se mais, nós quebrámo-nos em termos de Associação de 
Estudantes, e foi em conflito que estivemos, mesmo com alturas complicadas que a malta quase não se falava e aquelas coisas todas, depois claro (//) depois

Luís Mota: (//) Havia uma certa crispação.

Óscar Nunes: Houve, houve ali crispação clara e já uns com os outros e, portanto, nessa relação é evidente que isso surgiu. Depois entretanto, pronto, aquilo acabou, depois estivemos uns anos sem nos ver, sem nos vermos, e depois quando nos encontrámos, fizemos todos umas festas, não, isso depois passa, mas na altura isso notou-se muito».

A problemática pela voz de Alberto Sousa está no cerne das críticas às Experiências Pedagógicas, numa argumentação de defesa da Normalização, onde tudo decorreu na «maior normalidade» donde resultaram divisões pessoais que não ficaram "para a vida»:

«Alberto Sousa: [...] houve as primeiras eleições democráticas para a Associação de Estudantes, cada turma elegia um delegado e esses delegados formavam uma coisa chamada a Comissão Central de Alunos, mas podia ser um, um António, uma Maria ou um Zé que nunca se tinham visto senão nos corredores da Escola, que não tivessem um projecto comum, não tivessem uma ideia comum, esses é que eram os representantes dos alunos, a, a, logicamente quando se fizeram as primeiras eleições, apareceram listas, de pessoas que se identificavam minimamente com alguns princípios, queriam determinados objectivos, atingir determinados objectivos, e fizeram-se as primeiras eleiçôes em que uma lista de que eu fazia parte ganhou as eleições com cerca de $75 \%$ dos votos, mas tudo sempre da mesma, da, da maior normalidade e sem, pequenas divisóes pontuais na altura, pessoais, entre alguns elementos mas que nem sequer ficaram para a vida e as pessoas hoje convivem todas, logo passados uns anos, conviviam todas (hem) independentemente dessa divisão, isso para dizer que não foi uma divisão muito vincada $[\ldots]$ ».

E discute criticamente a estrutura e funcionamento da Comissão Central de Alunos - órgão existente durante as Experiências Pedagógicas:

«Luís Mota: Tu estavas-me a dizer em termos de intervenção escolar, por que, até por que és o primeiro entrevistado que me refere essa situação, a primeira Associação de Estudantes, do período 74-75 não era uma Associação de Estudantes, por aquilo que tu disseste.

Alberto Sousa: Não, não, não era a Comissão Central de Alunos que era um aluno eleito em cada turma, cada turma atirava um para uma Comissão Central de Alunos, eu fui eleito no $1^{\circ}$ ano, também na minha turma, como delegado à Comissão Central de Alunos, era o delegado da turma X, mas encontrei lá pessoas que, quer dizer, a Comissão Central de Alunos, não era (.) (//) digamos, não era,

Luís Mota: (//) Não era homogénea.

Alberto Sousa: não era homogénea e permitia toda, toda (ham) permitia todas as influências que os professores quisessem fazer, os professores podiam condicionar a nível de cada turma o voto, que era muito mais fácil condicionar o voto a grupos de quinze, vinte pessoas, do que condicionar a um universo de trezentos, que eram o $1^{\circ}$ e $2^{\circ}$ ano da Escola, e no meu tempo já o $1^{\circ}, 2^{\circ}$ e $3^{\circ}$ ano da Escola, quatrocentos 
alunos, às vezes, trezentos alunos, quatrocentos, ora com, a nível de uma turma é muito mais fácil às vezes uma eleição numa turma de vinte ganha-se com cinco votos, portanto, esse tipo é que ia representar aqueles vinte, mais cinco do outro lado, mais cinco do outro lado, a, e isso não, não é democrático, quer dizer, é uma forma de democracia em pirâmide, mas que não, não é tão democrático como uma lista que se apresenta à Escola inteira e que a Escola inteira vota e que tem, a lista $\mathrm{A}$, a lista $\mathrm{B}$, a lista $\mathrm{C}(/ /)$ para escolher,

Luís Mota: (//) Claro.

Alberto Sousa: e isso (//), e que leva um programa atrás e tal,

Luís Mota: Com programas definidos.

Alberto Sousa: ali não havia programas nenhuns, era o tipo mais engraçado da turma ou o tipo mais, mais, que falava mais ou que dava mais nas vistas, até por que as eleições eram logo feitas ali em, no princípio do ano, ao fim de três semanas de aulas, portanto, era fácil controlar aquilo e eu penso que, por essa Comissão Central de Alunos onde está, onde estive, não tenho dúvidas que havia ali um certo grupo que mantinha a posição de força ali».

Sublinha, ainda, o "funcionamento em células mais reduzidas que tem também uma componente ideológica» como ele explica:

«Luís Mota: E em termos dos diferentes departamentos da própria Escola tipo secção de Reprografia, Bar a (.)

Alberto Sousa: Aí não me recordo (ah) eu tenho ideia que nalgum tempo, havia um representante dos alunos nessas secções, mas, mas não tenho a certeza absoluta e não sei era antes se era depois, creio que até era antes, que haveria, portanto, no período de 75-76, que haveria um representante dos alunos no Bar, não sei quê e tal, mas era toda, o que eu queria dizer com isto, é que era toda uma lógica de funcionamento diferente, a partir do momento que a Associação de Estudantes não se reúne numa sala fechada, fecha a porta, e combina o que é que vai fazer, quer o director goste quer não goste, quando é um elemento da turma que vai lá e que depois vai à turma levar as conclusôes, vota na turma, volta à Comissão Central de Alunos, quer dizer são lógicas completamente diferentes e que estão inseridas num, num (//) num princípio (.)

Luís Mota: (ah) quer dizer, as decisões da Comissão estão dependentes das (//), da aprovação nas turmas.

Alberto Sousa: (//) Muitas vezes era, por que as pessoas não tinham um programa não sabiam o que é que os seus colegas pensavam sobre uma questão que tinha sido colocada ali pela primeira vez, então vamos ver o que é que a turma pensa, depois para a semana voltamos a trazer a opinião da turma, e era assim um bocado, e que tem a até a ver, quer dizer, é uma forma de funcionamento em células mais reduzidas que tem também uma componente ideológica, como nós sabemos, não é.

Luís Mota: Claro.

Alberto Sousa: (ah) não havia um Parlamento, não é, digamos, en, enquanto a Associação de Estudantes é um Parlamento, qualquer pessoa entra, põe questões, faz-se uma RGA, não sei quê, antes não era assim, era a turma pelo delegado, o delegado pelos outros delegados, depois o, a Comissão Central de Alunos também creio que tinha o, já não sei como é que isso funcionava bem, para te ser franco, mas creio que 
tinha um presidente ou, ou três pessoas que essas é que iam falar com o director, portanto, era, era um lógica completamente diferente e, cada turma não se repre

Luís Mota: Era uma coisa vertical, não é?

Alberto Sousa: Sim, cada aluno não se revia na Comissão Central de Alunos, quando muito revia-se no seu (//) delegado de turma,

Luís Mota: (//) No seu representante.

Alberto Sousa: uma coisa assim, enquanto a Associação, havia os que gostavam da Associação que tinham votado nela e os que não gostavam (//), pronto,

Luís Mota: (//) Claro, é evidente.

Alberto Sousa: mas era a Associação de todos os estudantes».

Concluo o meu excurso com uma nota em que pretendo sublinhar a recusa dos actores sociais em se deixarem remeter ao silêncio e à invisibilidade, afirmando o valor e legitimidade das suas posiçôes e diferenciando-as. Centrada na questão das classificações de curso, narra Francisco Quaresma, professor na década de sessenta:

«Luís Mota: Sr. Dr. já agora, a propósito de alunos e falou há um bocado nas prendas por causa das notas, como é que era a avaliação, qual é que era a concepção de avaliação que havia aqui na Escola (//)

Francisco Quaresma: (//) Ora, era um bocadinho exagerada, na minha maneira de ver, era exagerada mas, (eh) havia uma razão para isso. Como sabe, as médias finais, as notas finais eram dadas numa reunião dos directores, os directores levavam as informaçôes da Escola para Lisboa e depois entre si, os directores na presença do director-geral, na presidência do director-geral, combinavam, bom, este ano vamos dar tantos $\%$ de 17 , tantos $\%$ de 16 , tantos $\%$ de 14 , (eh) normalmente não reprovava ninguém, não é, porque todos aqueles indivíduos que chegavam ao fim do ano normalmente passavam, com maior ou menor nota passavam, portanto, a nota da Escola era apenas uma informação, (eh) um aluno que fosse bom aluno aqui na Escola, pois nesse rateio geral (eh) ficaria com o dezassete ou dezasseis, com a nota máxima mas, se houvesse muitos indivíduos com uma nota boa já ultrapassava aqueles tantos \% combinados por eles, portanto, baixaria e tal, enfim. Ora, portanto, aí não se pode dizer que houvesse exagero, não é, porque se, se houvesse exagero isso era com, (eh) da combinação resultante entre eles, não é. Agora, propriamente aqui dentro, durante o curso, havia, havia assim uns exageros, os alunos queixavam-se que eram mais favorecidos o, o fulano ou cicrano ou beltrano, que havia, não, não, enfim, eu não sei verdadeiramente se

[Interrupção devido a quebra de privacidade do espaço de realização da entrevista]»

Esta interrupção na entrevista viria a revelar-se importante, pois acabou por conduzir o nosso entrevistado em direcção à situação da classificação final e à reunião do júri único, em Lisboa, em que o nosso entrevistado — relatando uma situação vivida onde ele, de algum modo, desempenha um papel de interface nas relações interpessoais - nos oferece uma visão das reuniōes do júri único e nas classificações a atribuir no período do Estado Novo, na década de sessenta, em seu entender, se jogava mais do que uma simples atribuição de uma classificação final a alunos(as)-mestre(as) e poderia adquirir relevância as relaçôes interpessoais e os posicionamentos de cada um, 
nomeadamente dos directores, em face da situação política e das elites do regime. Atentemos:

«Luís Mota: Podemos recomeçar Sr. Dr..

Francisco Quaresma: Havia, houve até um ano em que houve uma desinteligência entre o director-geral e o Dr. Loureiro, já não sei a que propósito que se pegaram um bocado, não é, é claro que o director-geral estava um bocado manietado porque o Loureiro estava ligado ao Santos Costa, não é, mas por outro lado, houve um atrito e sei que vão para essa reunião e o director-geral, como de costume, diz então este ano vamos (eh) assentar nisto, tantos \% de 16, tantos \% de 15 e tal, sim senhor, e depois, começava isto: «Dr. Loureiro este aluno que nota tem em Psicologia? Tem dez em Psicologia, não é» - que era a minha nota, eu era sempre uma notas desgraçadas $(($ sorri $))$. «Pronto, então esse aluno fica com dez, acabou, o resto não me interessa mais» e tal. Eh e chegámos a uma determinada altura em que os alunos aqui da Escola estavam corridos a dez, onzes, dozes, (eh) e não passava daquilo. Esse rapaz Barros, telefonou-me e disse-me: «(oh), tu fazes ideia do que se está aqui a passar, a tua nota é que está a comandar aqui a nota da Escola, a Escola aí está a ficar com um nível muito baixo em notas». Eu: "(oh) pá explica-me lá bem isso.». «Olhe...», explicou-me o que se passava. Bom, eu telefonei para o director-geral: "(oh) Sr. director-geral, eu precisava muito urgentemente de falar com o Sr. director-geral, se eu for a Lisboa, recebe-me já?». "(ah) recebo, venha venha». Cheguei lá e disse: «((oh)) Sr. director-geral, para, consta-me que o Sr. Dr., o Sr. director-geral, que está a fazer base, muito, muita base na minha nota». "Pois, a sua nota é a única que me merece confiança». "((oh)), Sr. director-geral mas não pode fazer isso, porque eu dou notas baixas exactamente para travar as outras mas, assim bem vê, isso não pode ser porque os alunos da Escola de Coimbra em relação aos outros...". "Realmente, eu nunca tinha pensado isso». "((oh)) Sr. director-geral ((ri)) mas isso é, é elementar». «Mas então as suas notas...!». «Pois é, eu dou notas baixas durante o curso, exactamente para ver se os outros também baixam porque às vezes há notas disparatadas, não é, e as minhas notas eu tenho consciência...". "Bom, então quanto é que você lhe parece, que se deve aumentar à sua nota?». "((oh)) Sr. director-geral, (eh, eh) eu não sei, talvez aí dois, três valores». "Sim, (ah) está bem, então eu vou pensar...". "(oh) Sr. director-geral mas tenha paciência, pense nisso de maneira que os alunos da Escola de Coimbra, que nem devem ser melhores nem piores, devem ser iguais aos outros, que não saiam com uma nota, porque aquela nota marca-os depois para o resto da vida». Bom, efectivamente, as coisas compuseram-se, (eh) (eh) alinharam mas havia, havia assim aqui um, umas notas um bocadinho des, disparatadas, havia, havia, dezo, na frequência dezoitos e dezanoves, isso era um, ora de alunos (eh) (//)

Luís Mota: (//) Que saíam daqui (//)

Francisco Quaresma: (//) Pois.

Luís Mota: e depois eram corrigidas na reunião com o director-geral.

Francisco Quaresma: Depois na reunião, não é. É claro mas depois o director-geral também baseava-se na minha nota $(/ /)$

Luís Mota: (//) Pois, o que prejudicava.

Francisco Quaresma: Está claro, nem oito nem oitenta, ora vamos lá ver. ((ri)) Sim, senhor». 


\section{Concluindo...}

A análise de conteúdo das páginas do Rumo reenvia para a ideologia e representações do Estado Novo, num sentido totalizador e totalizante. A moral católica tem um carácter constitutivo e a religiāo católica é assumida como raiz. No conceito de «educação nacional» é possível identificar a inculcação ideológica, a carga simbólica e a presença da temática oficial. Ao nível do quotidiano emergem o peso da vivência católica patente na consagração anual ao sagrado coração de Maria e a mudança de edifício, espaço para uma narrativa cerimonial bem ao jeito do Estado Novo. Projecta-se uma imagem da mulher no lar, a mãe, a cônjuge e a primeira educadora, onde não faltam sugestōes para afazeres domésticos, a decoração, a arrumação e receitas de culinária. A política afina pelo mesmo diapasão, exprimindo um nacionalismo corporativo, pugnando por um ruralismo compaginado com a exaltação da pátria enquanto nação, sustentando um universalismo cristão lusíada, numa abertura ao lusotropicalismo. As narrativas do Rumo, com raras excepções, traduzem o investimento simbólico e ideológico do Estado Novo.

A leitura memorialística conduz a uma dimensão emocional e afectiva, resultante da experiência física e psicológica, que obriga a complexificar os julgamentos sem os condenar a um relativismo integral. Julgamentos resultantes dum encadeamento singular de circunstâncias, interesses próprios ou do seu grupo, procedendo duma análise e de uma selecção, com manifesta preocupação com o detalhe e o exemplo, traduzindo uma verdade sobre a vida dos homens, intersubjectiva e não referencial, expressão de posicionamentos e dilemas pessoais. Contributo importante para humanizar e vivificar as narrativas.

Os entrevistados, inicialmente localizados mais próximos desta ou daquela corrente de opinião, reconstituíram momentos e tensões, sendo visíveis as hesitações e inflexões no raciocínio e construção da argumentação - sem esquecer a sua dimensão contingente - tendo a preocupação de destacar o seu papel e sublinhando a preponderância da sua acção face à realidade vivida, transportando para a narrativa as dimensões emocional e afectiva, sobressaindo revolta, sentimentos de injustiça, ressentimentos - é do sofrimento que vem a recordação - obrigando e forçando muitas vezes a que, também nós assumíssemos posiçôes face aos acontecimentos ou ideias. Nem sempre foi fácil manter esse distanciamento e a existência de um conhecimento mútuo anterior não facilitou.

\section{BIBLIOGRAFIA}

BILLIG, Michael - Collective Memory, Ideology and the British Family. In MiddLeton, David; EdWARDS,

Derek org. - Collective Remembering. London: Sage, 1990.

BILlig, Michael - Ideology and Opinions. Studies in Rhetorical Psychology. London: Sage, 1991.

BILLIG, Michael - Methodology and Scholarship in Understanding Ideological Explanation. In ANTAKI, Charles org. - Analysing Everyday Explanation. A Casecook of Methods. London: Sage, 1988.

BILlig, Michael et al. - Ideological Dilemmas. A Social Psychology of Everyday Thinking. London: Sage, 1988.

CATroga, Fernando - Memória, História e Historiografia. Coimbra: Quarteto Editora, 2001. 
Catroga, Fernando - Ritualizações da História. In Torgal, Luís Reis; Mendes, José Maria Amado; Catroga, Fernando - História da História em Portugal. Séculos XIX-XX. Lisboa: Círculo de Leitores, 1996.

GeERTZ, Clifford - A interpretação das culturas. Rio de Janeiro: Zahar Editores, 1978.

HalbWachs, Maurice - La Mémoire collective. Paris: Albin Michel, 1997.

HalbWachS, Maurice - Les cadres sociaux de la mémoire. Paris: Albin Michel, 1994 [1925].

LEPETIT, Bernard - Carnet des croquis. Sur la connaissance historique. Paris: Albin Michel, 1999.

LEPETIT, Bernard - De l'échelle en histoire. In REVEL, Jacques - Jeux d'échelles. La microanalyse à l'expérience. Paris: EHESS-Gallimard-Seuil, 1996.

Lepetit, Bernard - Histoire des pratiques. Pratique de l'histoire. In LEPETIT, Bernard - Les Formes de l'expérience. Une autre histoire sociale. Paris: Albin Michel, 1995.

LEPETIT, Bernard - Les Formes de l'expérience. Une autre histoire sociale. Paris: Albin Michel, 1995.

LEPETIT, Bernard - Une autre histoire sociale. In Correspondances. Bulletin cientifiques de l'IMRC, 1996. [Consult. 2006-02-18] Disponível em WWW: <URL: http://www.irmcmaghreb.org/corres/textes/lepetit.htm>.

Mendes, José Manuel de Oliveira - Do Ressentimento Ao Reconhecimento. Vozes, identidades e processos políticos nos Açores (1974-1996). Porto: Ediçōes Afrontamento, 2003.

Mendes, José Manuel de Oliveira - Perguntar e observar não basta, é preciso analisar: algumas reflexões metodológicas. Coimbra: Centro de Estudos Sociais, 2003.

Mota, Luís - A Escola do Magistério Primário de Coimbra (1942-1989). Entre Ideologia, Memória e História. Coimbra: Universidade de Coimbra, 2006. Dissertação de doutoramento.

NAMER, Gérard - Mémoire et Société. Paris: Méridiens Klincksiek, 1987.

ORTner, Sherry - Resistance and the Problem of Ethnographic Refusal. In Society for Comparative Study of Society and History 37 (1) (1995).

POLlaK, Michael - L'Expérience Concentrationnaire. Essai sur le maintien de l'identité sociale. Paris: Editions Métailié, 2000

POLlaK, Michael - Memória e Identidade Social. In Estudos Históricos. Rio de Janeiro, vol. 5, n. ${ }^{\circ} 10,1992$, pp. 200-212. [Consult. 2006-01-21]. Disponível na WWW: <URL:http://www.cpdoc.fgv.br/revista/ arq/104.pdf>.

POllaK, Michael - Memória, Esquecimento, Silêncio. In Estudos Históricos. Rio de Janeiro, vol. 2, n.o 3, 1989, pp. 3-15. [Consult. 2006-01-21]. Disponível na WWW: <URL:http://www.cpdoc.fgv.br/revis$\mathrm{ta} / \mathrm{arq} / 43 . \mathrm{pdf}>$.

RICOEUR, Paul - Ideologia e Utopia. Lisboa: Edições 70, 1991.

Ricoeur, Paul - La Mémoire, L'Histoire, L'Oubli. Paris: Éditions du Seuil, 2000.

SAntos, Boaventura de Sousa - A crítica da razão indolente. Contra o desperdício da Experiência. Para um novo senso comum: A ciência, o direito e a politica na transição paradigmática. Volume I. Porto: Ediçōes Afrontamento, 2002.

SANTOS, Boaventura de Sousa - Toward a New Common Sense. Law, Science and Politics in the Paradigmatic Transition. New York: Routledge, 1995.

SCHUDSON, Michael - How Culture Works: Perspectives from Media Studies on the Efficacy of Symbols. In Theory and Society 18 (1989), pp. 159-160.

Thompson, John B. - Ideologia e Cultura Moderna: teoria social na era dos meios de massa. Petrópolis: Vozes, 1995

TOdorov, Tzvetan - La mémoire devant l'histoire. In Terrain 25 (1995) 101-112.

Todorov, Tzvetan - Les Abus de la Mémoire. Paris: Arléa, 1995. 

Série

Documentos

Imprensa da Universidade de Coimbra

Coimbra University Press

2010

- U

C • 